

\title{
PLANO "COSTURA-VERDE"
}

\author{
GREEN LINK PLAN
}

\section{Naiara Luchini de Assis Kaimoti}

Arquiteta e urbanista (FAAC/Unesp), especialista do Programa de Capacitação em Arquitetura Paisagística e mestranda pela FAUUSP

e-mail: naiaraluchini@uol.com.br

\section{RESUMO}

Essa pesquisa fez parte dos requisitos para a conclusão do curso de Capacitação para Professores de Arquitetura Paisagística, Módulos I a IV, ocorrido no período entre janeiro de 2004 e julho de 2005 e promovido pela Fundação para a Pesquisa Ambiental (Fupam), Faculdade de Arquitetura e Urbanismo da Universidade de São Paulo (FAUUSP) e pela International Federation of Landscape Architects (IFLA). O trabalho teve como objetivo aplicar alguns conceitos do conteúdo teórico-prático apresentado durante o curso em uma área específica: a bacia do Córrego da Água Comprida, no Município de Bauru-SP. Como resultado, foram sugeridas diretrizes para nortear o planejamento urbano por meio da compreensão da paisagem com uma integração do meio biofísico e do meio social por uma "conexão verde".

Palavras-chave: Paisagem, espaços livres, compreensão da paisagem, desenvolvimento sustentável, conexão verde.

\begin{abstract}
This research was part of the requirements for the conclusion of the Course of Landscape Architecture Training for Teachers, Modules I to IV, which took place between January of 2004 and July of 2005, sponsored by the Foundation for Environmental Research (Fupam), College of Architecture and Urban Planning of the University of São Paulo (FAUUSP), and the International Federation of Landscape Architects (IFLA). The research goal was to apply some of the theoretical-practical concepts presented during the course in a specific area: the Água Comprida creek basin in the district of Bauru-SP. As a result, some suggestions were made to guide the urban planning through the understanding of the landscape with an integration of the biophysical and of the social environment through a "green connection."
\end{abstract}

Key words: Landscape, open spaces, landscape understanding, maintainable development, green conexion. 


\section{Cinzeiro}

Quando meus olhos voltaram a ver aquela paisagem, algo se descortinou para mim....

$\bigcirc$ que outrora era apenas uma paisagem degradada, seca, com apropriações ciganas, repentinamente se transformou quando me tornei estrangeira no lugar. Um pouco da vegetação havia se recuperado; não sei se as espécies que lá cresceram são nativas ou se, algumas que, de estrangeiras que também são, se fincaram como solução amena para aquela fenda. Um rasgo enorme, engolindo tudo a cada gota de chuva... Mas que visão é essa?

E então, algo muito sutil aflorou e, só quem a lê, pode enxergar: os galhos, tortuosos e retorcidos de uma pequena porção de cerrado, acuado pela ação "hurbana"1. E tal como o brilho da manhã, o vale se abriu e quis mostrar sua beleza, agredida, mas persistente...

Foi por LER A PAISAGEM que nasce aqui uma pequena diretriz para os novos rumos da Paisagem Urbana desse lugar. Eu li as entrelinhas, lá estava o cerrado, (re) conheci Bauru. Era o cinzeiro ${ }^{2} . . . "$

Naiara Luchini de Assis Kaimoti

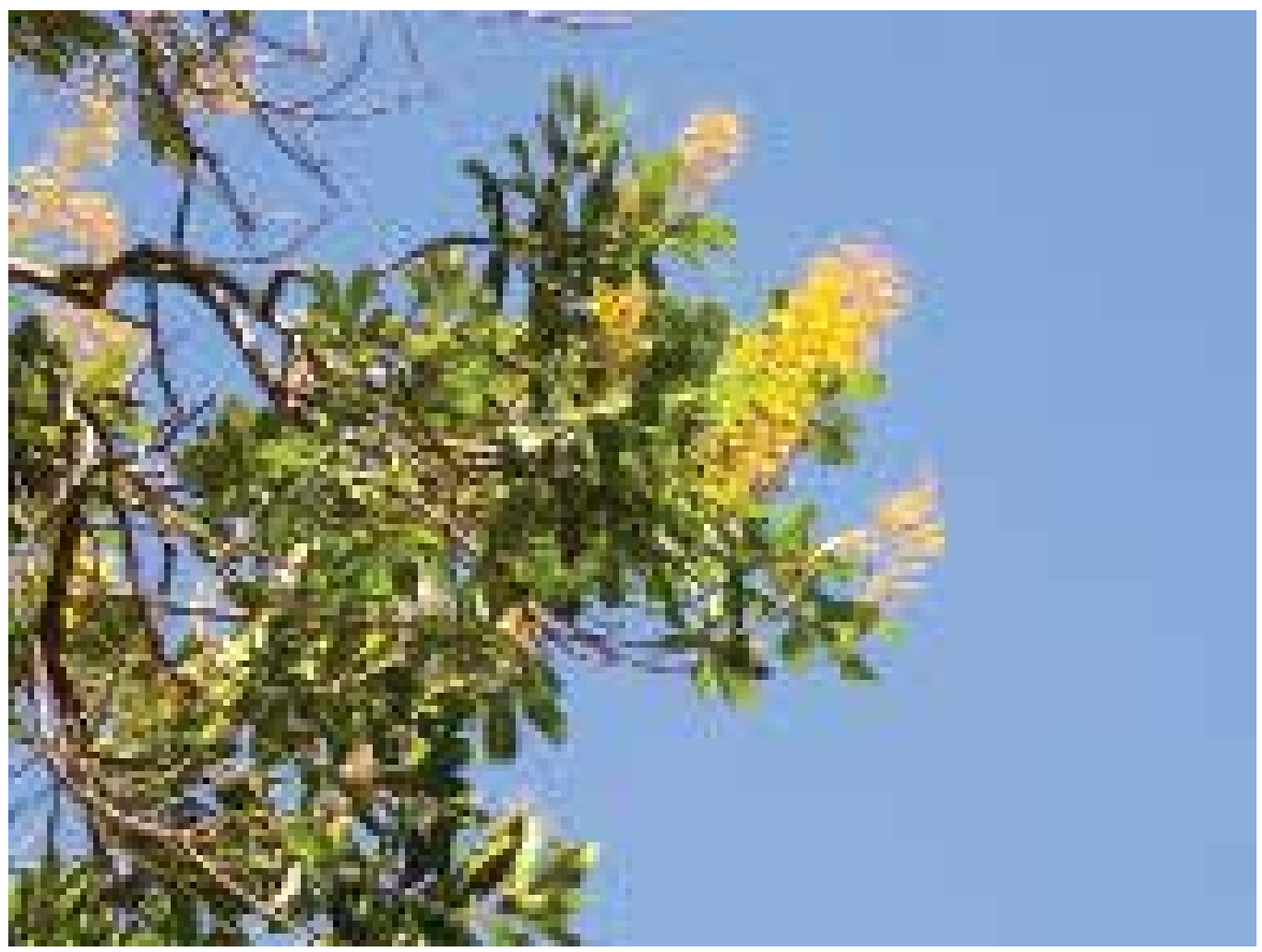

Figura 1: Flor de cinzeiro (Vochysia tucanorum) Crédito: Autora 


\section{INTRODUÇÃO}

A vida cotidiana na cidade acontece por um incontável número de informações vindas das mais diversas fontes que nos cercam. A percepção visual, dentro do meio urbano, talvez se configure como o melhor exemplo do modo como diversas imagens associadas podem gerar diferentes modos de interpretação de um determinado lugar. Na era da globalização, a velocidade dos eventos pode, nesse contexto, favorecer uma leitura parcial e desconecta da realidade em que ocorrem as relações de convívio. No meio urbano, as diferentes paisagens acabam por não ter uma diferenciação concreta entre si. Os recursos visuais da propaganda, com fortes apelos consumistas, permitem levar a uma perda das especificidades de cada lugar, uma vez que os estereótipos visuais do consumo são mais convincentes e atraentes, e estão disseminados por quase toda a cidade. Cria-se, então, uma idéia superficial, ou até mesmo homogênea, do lugar onde se mora, estuda, trabalha ou se diverte. "A cidade se transforma no local do não-pertencimento, da desorientação, da repetição de padrões preestabelecidos, vazio de referências arquitetônicas e urbanísticas tanto nas áreas centrais como nas periferias, onde foram se apagando quaisquer vestígios de identidade histórica ou características da base biofísica do sítio da cidade, elementos que poderiam servir de base para uma maior diferenciação espacial." (OSEKI; PELEGRINO, 2003)

Como espectadores e atores da chamada pós-modernidade ${ }^{3}$ urbana, fazemos parte de uma paisagem transformada, repleta de significados, cujos cenários a acompanharem-nos diariamente refletem a ação antrópica ao longo do tempo. A paisagem pode ser entendida não só por seu aspecto natural (rios, lagos, bosques, matas, campos), mas também como o "resultado do equilíbrio entre múltiplas forças e processos temporais e espaciais" (LEITE, 1994, p. 7). Uma verdadeira simbiose entre os elementos físicos naturais e seus processos correlatos; uma simbiose entre o homem e suas relações com a sociedade e o mundo natural.

Assim, no decorrer dos períodos, "a percepção do tempo, do espaço e da natureza muda com a evolução cultural, o que exige a procura de novas formas de organização do território que melhor expressem o universo contemporâneo, formas que capturem o conhecimento, as crenças, os propósitos e os valores da sociedade" (LEITE,1994, p. 7). Ainda nas palavras desse autor, natureza e cultura conferindo forma e individualidade aos lugares; uma interação constante entre os ritmos de produção, transporte e consumo com os ritmos climáticos, biológicos e hidrológicos, de modo que a resultante consiste em paisagem moldada "cujos padrões de produção e utilização variam de acordo com o contexto específico de cada sociedade" .

Nesse início de século 21 ainda predomina, em considerável parte da população, um grande desconhecimento dos ritmos que o meio natural exerce dentro do contexto urbano. Na verdade, periodicamente se conhece apenas sua catástrofe, mas não se compreende a verdadeira causa de tantos infortúnios. Nesse sentido, o ambiente urbano também é um ecossistema. Nele interagem e convivem as comunidades biótica e abiótica, nas quais o sistema de espaços livres se apresenta como um conjunto complexo, 
cujo potencial sistêmico reside na conectividade e na complementaridade entre seus elementos dispersos.

Com esse trabalho, busca-se poder incentivar novos estudos para os córregos e rios que permeiam o tecido urbano de grande parte das cidades de médio porte da atualidade. Assim, a identificação das especificidades de cada curso d'água pode gerar, em uma escala maior, uma grande conexão "verde" por toda a cidade. As conseqüências desse grande sistema recairiam em melhores espaços urbanos para a recreação e o lazer da população urbana, com um maior respeito pelos fenômenos naturais, tão ignorados pelos atuais planos das cidades.

\section{O Lugar}

"Não só creio que a forma equilibra o processo na natureza, como também penso que nosso sentido de estética deriva da natureza.

(...) Contemplo a terra e seus processos vitais como um modelo para o processo criativo." 4 Lawrence Halprin

\section{A escolha da àrea}

Diante do tema proposto para análise de uma situação de microbacia, foi escolhida, para esse estudo, a paisagem formada pelos vazios urbanos do fundo de vale do Córrego da Água Comprida, na cidade de Bauru, interior do estado de São Paulo (Figuras 2 a 4). No caso de Bauru, vários córregos e cursos d'água estão completamente inseridos na malha urbana. Entretanto, a maioria se apresenta como áreas degradadas devido

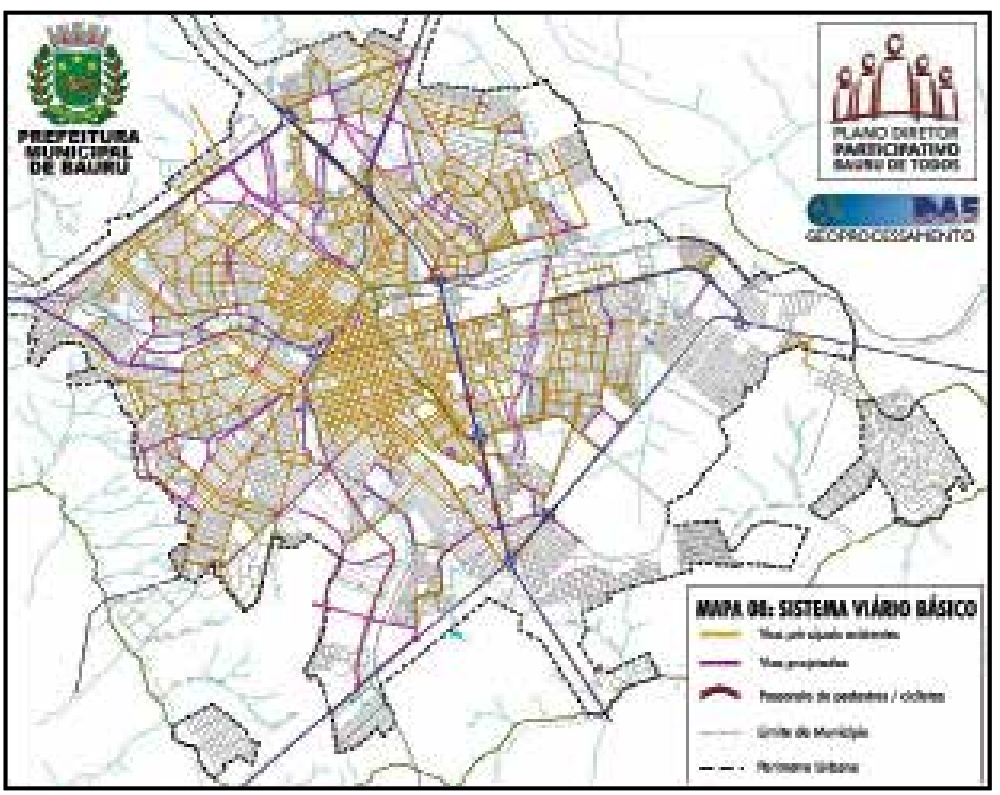


ao lançamento de esgoto e lixo em seus leitos e também pelo assoreamento provocado pela devastação da mata ciliar original. $O$ fato fica, então, ainda mais evidenciado pela ausência de uma proteção ambiental mais severa e efetiva, mesmo sendo citado no próprio Plano Diretor de Bauru (1996)5), que a "vocação natural dessas áreas são parques verdes onde se prevêem o transbordamento natural de seus leitos nos períodos chuvosos e, quando não, áreas de lazer para a população".

A pesquisa teve como objetivo oferecer diretrizes para o planejamento do desenvolvimento sustentável das áreas residuais em áreas de fundo de vale, de modo que o projeto paisagístico seja o elo entre o meio físico e o meio social. Em outras palavras, o paisagismo atuando como instrumento de recuperação ambiental e integração social em toda a microbacia do córrego em questão, revertendo em qualidade de vida e em um desenvolvimento sustentável para o ecossistema urbano. Uma "costura" literalmente verde unindo suas margens.
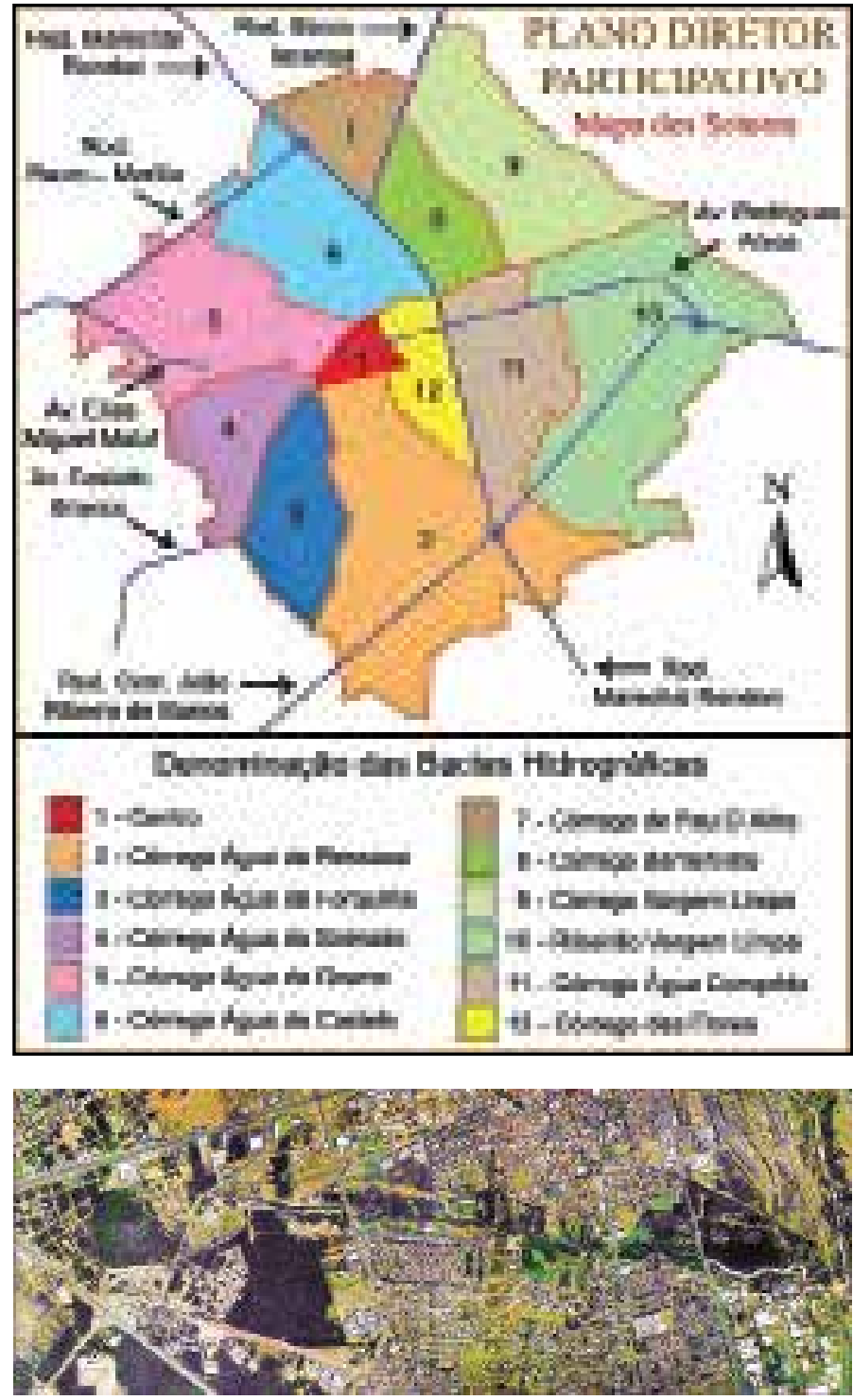

Figura 3: Mapa dos setores e bairros Fonte: http://www.bauru.sp.gov.br/ planodiretorparticipativo
Figura 4: Foto aérea: bacia do córrego da Água Comprida Crédito: Grupo alunos TPI-3 
A pesquisa sugere um estudo interdisciplinar na elaboração de diretrizes projetuais para o planejamento da paisagem urbana da cidade de Bauru por meio da arquitetura paisagística. Enfatiza-se que, além dessa, existem outras áreas de interesse pertinentes ao assunto e, necessariamente, deveriam ser contatadas em eventual aplicação real do plano de estudo aqui proposto.

Para tanto, a área escolhida se faz pertinente à pesquisa por uma série de fatores, entre eles:

- Apresentar-se, fisicamente, como um "elo" em potencial entre a maior porção de cerrado à montante (próximo ao campus da Unesp e APA do Zoológico e Jardim Botânico de Bauru) e o Horto Florestal (próximo à jusante, no deságüe com o rio Bauru), importantes áreas de estudo e preservação da fauna e flora bauruenses;

- pelo fato de o córrego ainda possuir pequeno remanescente de vegetação nativa (cerradão);

- estar em posição privilegiada e estratégica de ligação entre o centro e dois acessos importantes da cidade (avenidas Nações Unidas e Rodrigues Alves);

- configurar-se como área de grande valorização imobiliária, principalmente com o crescimento acelerado de condomínios verticais e horizontais, avançando sobre o córrego e a área de vegetação remanescente;

- pelo vale ser objeto de grande impasse entre a comunidade e o poder público, uma vez que, em 1991, Áreas de Preservação Permanente (APP) foram indevidamente negociadas e desapropriadas com o propósito da construção do Parque da Água Comprida e de uma avenida-parque, em um total de $129.457 \mathrm{~m}^{2}$. O projeto, que, felizmente, não saiu do papel, é anterior às diretrizes do Plano Diretor de 1996, que, por sua vez, trata das áreas de parques urbanos com pouca profundidade quanto ao seu planejamento e gerenciamento. A especulação imobiliária investiu em empreendimentos pós-plano diretor que não passaram por um critério de avaliação para sua implantação e avançou sobre áreas non aedificandi. A proposta para o parque ratifica sua falta de concepção e preocupação ambiental, uma vez que ignora a presença de 23 nascentes de caráter permanente na área desapropriada e permite a construção de uma avenida nessa mesma área (ALVES, 2001, p. 212);

- pelo fato de a cidade ter sua configuração física urbana toda recortada por rios e córregos que se interligam e, historicamente, essas áreas foram desprezadas pelo mercado imobiliário de modo que grandes vazios urbanos se formassem nos vales desses cursos d'água, conseqüência direta dos interesses econômicos e políticos para a expansão da chamada "cidade sem limites" (ALVES, 2001, p. 29).

\section{A escolha do referencial teórico}

A partir do conteúdo teórico-prático apresentado durante todo o curso de capacitação, destaca-se como fundamental para esta pesquisa o referencial que compreende a Ecologia da Paisagem, iniciada por Frederick Law Olmsted em 1864 e, posteriormente, difundida pelos estudos de Philip Lewis e lan MacHargh (década de 1960), Eugene 
Odum (início dos anos 70), Michael Hough, Anne Spirn e John Lyle (final da década de 1970)6 e, mais recentemente, Julius Fabos, R. T. T. Forman e Kaplan \& Kaplan. Desse modo, os diferentes conceitos podem estar presentes nas diferentes etapas de análise e interpretação do sítio. Alguns desses conceitos podem ser aqui relacionados, uma vez que, durante os trabalhos desenvolvidos nesse curso, os processos de aprendizado se mostraram muito pertinentes ao tema aqui pesquisado. São eles:

- O conceito de "Mancha-Corredor-Matriz" (FORMAM; GODRON, 1986) e Greenways, exposto pelo professor Jack Ahern (University of Massachusetts, USA);

- os conceitos de "Leitura da Paisagem e Projeto Eco-Revelatório", exposto pelo professor Kenneth McCown (California Polytechnic State University, Ponoma, USA);

- o conceito de "Mapas Comportamentais", exposto pelo professor Robin Moore (College of Design of North Carolina State University, USA);

- o conceito de "Unidade de Paisagem", exposto pelo professor Robet Brown (School of Environmental Design, University of Guelph, Canada);

- o conceito de "Espírito do Lugar", exposto pelo professor Darrel Morrison (College of Environment and Design, University of Georgia, USA);

- os exemplos de Planejamento Ambiental, expostos pelos professores Cecelia Paine e James Taylor (School of Landscape Architecture, University of Guelph, Canadá).

Certamente existem inúmeras formas de planejar-se a paisagem, porém, para este estudo, acreditamos que a reunião dos referenciais acima mencionados, aplicados em processos específicos de análise do sítio, possa gerar resultados mais satisfatórios e inerentes à paisagem em questão. Ao usar esses conceitos como método de (re)conhecimento da área estudada, pode-se também aplicá-los nas demais microbacias dos córregos que cortam a cidade, onde, certamente, os resultados podem não coincidir em vários aspectos. Dessa forma, parte-se do pressuposto de os resultados obtidos refletirem as especificidades do lugar e a situação real de cada localidade expressar uma demanda diferente entre si, principalmente no que diz respeito às potencialidades econômicas, infra-estrutura e recursos naturais.

A conexão entre uma paisagem e outra se torna possível realizar quando uma análise maior identifica e conecta os diferentes espaços, formando, assim, um grande sistema para toda a cidade. Esse sistema se concretiza pelo inter-relacionamento dos diferentes ecossistemas urbanos, formando um sistema de espaços livres cuja função maior é a proteção dos recursos naturais (e seus processos) com a conscientização da população, que exerce papel fundamental para o equilíbrio da vida urbana.

\section{Breve colocação sobre o referencial escolhido para a proposta: A ecologia da paisagem}

A paisagem denota a escala perceptível entre os processos humanos e os naturais. Com a evolução das civilizações, as comunidades se instalaram sobre a paisagem natural na qual aprenderam a utilizá-la assegurando - em princípio - sua perenidade. Ao fazê-lo, sobre um determinado funcionamento ecológico, desenvolveram determi- 
nada cultura que deixaram inscrita na paisagem, dando origem à paisagem cultural. Nesse sentido, Magalhães (2001, p. 320) observa quando diz que ecologia e cultura são, portanto, as duas vertentes que constituem os primeiros pressupostos da forma da paisagem.

O pensamento se completa somando as contribuições de Pellegrino quando o mesmo afirma:

"a combinação dos aspectos naturais e culturais que criam a paisagem inclui elementos visíveis à vivência cotidiana tais como os campos, as matas, os lagos, os rios e as cidades. (...) A maneira pela qual estes elementos são apropriados reflete a cultura de seus habitantes.' Atualmente, 'a atividade de planejamento da paisagem, baseada em princípios conservacionistas, requer cada vez mais a tomada de decisões sobre alternativas para o redesenho paisagístico dos espaços livres urbanos', apoiadas no uso racional e sustentado dos recursos ambientais." (PELLEGRINO, 2000, p. 167)

De acordo com esse autor, o uso racional e sustentado da paisagem significa, portanto, o melhor uso, considerando-se todos os aspectos que condicionam a conservação dos recursos, ou seja, reconhecer a necessidade de proteção dos recursos naturais e culturais de forma que o atendimento dos interesses do presente não comprometa a capacidade das futuras gerações de atenderem às suas necessidades. Para ele, o planejamento ecológico da paisagem é a criação de uma solução espacial capaz de manejar as mudanças dos elementos da paisagem, de forma que as intervenções humanas sejam compatibilizadas com a capacidade dos ecossistemas em absorverem os impactos advindos das atividades previstas, e de manter-se a maior integridade possível dos processos e ciclos vitais que ocorrem em seu interior, sempre tendo como referência o contexto regional do qual fazem parte (PELLEGRINO, 2000, p. 168). A ecologia da paisagem surge "como tentativa de traduzir princípios ecológicos para a escala prática dos planejadores e arquitetos, visto que a maioria dos ecologistas não pensa visualmente, fazendo com que a informação ecológica seja dificilmente organizada de forma a ser imediatamente útil à intervenção" (PELLEGRINO, 2000, p. 167).

E para finalizar essa breve colocação, cita-se:

"Com sua expansão na última década do século 20, a ecologia da paisagem emergiu como uma importante ferramenta para planejadores e arquitetos paisagistas no manuseio de informações coletadas sobre uma determinada área, permitindo que esses pudessem analisá-las, interpretá-las e realizar proposições na escala da paisagem urbana e regional. Assim, pôde-se responder ao desafio da criação de um modelo que é uma linguagem espacial a permitir a comunicação entre as diversas disciplinas e os tomadores de decisões." (PELLEGRINO, 2000, p. 168) 


\section{O Real \\ "O tempo é inerente à paisagem." ${ }^{7}$ \\ Jack Ahern}

\section{A pesquisa}

Para a obtenção dos dados a partir do levantamento das condições biofísicas e sociais da bacia do Córrego da Água Comprida, foi sugerida uma divisão por etapas desse processo. As duas primeiras foram adequadas ao roteiro proposto por Oseki e Pellegrino (2003). A terceira etapa, de caráter mais subjetivo, foi uma compilação das diversas propostas trazidas para as aulas do curso realizado e que se julga serem as mais adequadas na obtenção de experiências sensíveis por parte da população do lugar. Por último, propôs-se um esquema-síntese que expressa o processo sugerido para o (re)conhecimento de determinadas especificidades do lugar as quais auxiliariam no traçado da leitura das paisagens a serem resgatadas, preservadas e/ou valorizadas.

Figura 5: Esquema para análise e interpretação do lugar

ANÁLISE (por)

ANÁLISE (por)

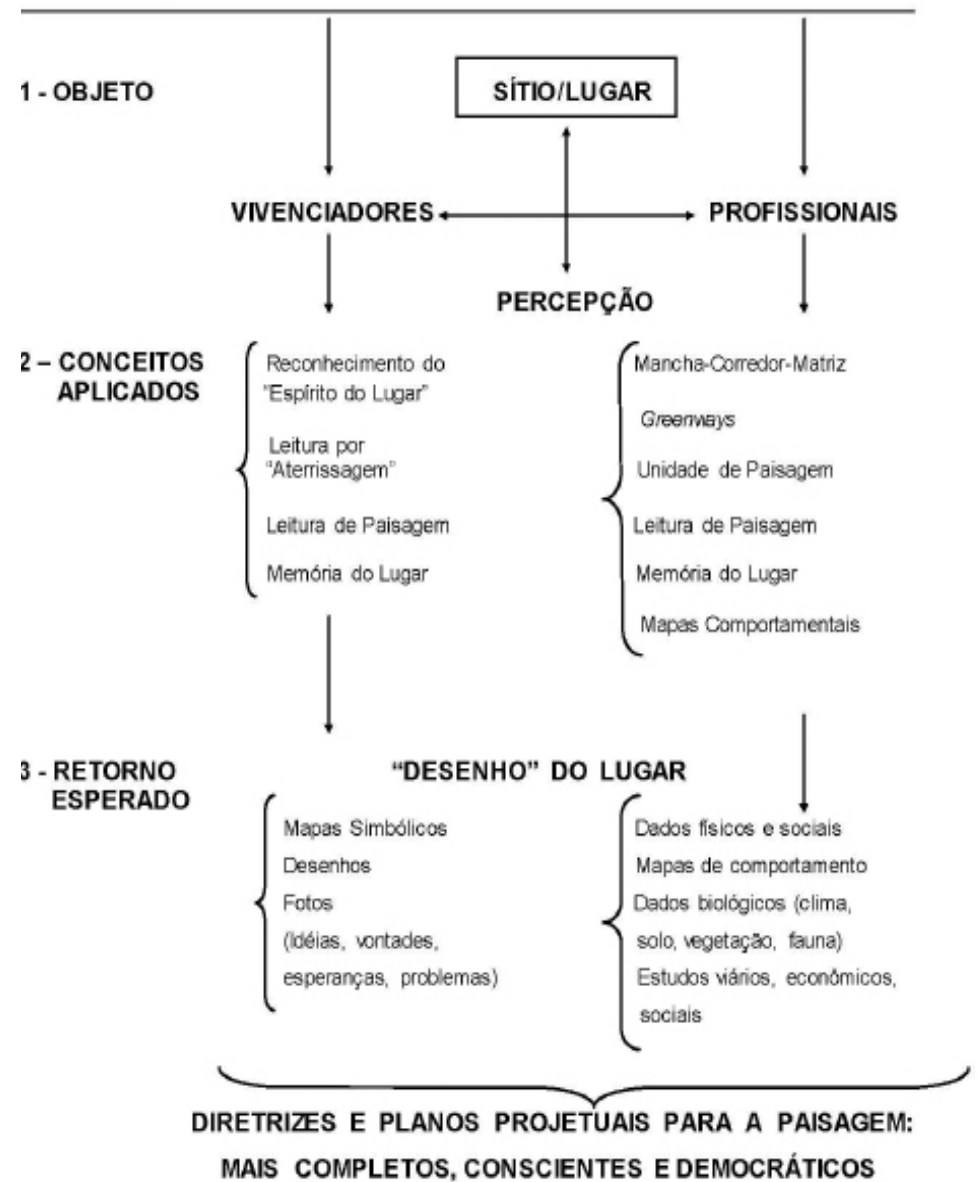




\section{ETAPA 1: Localização da área de estudo na região}

Levantamento e análise dos dados referentes aos aspectos mais relevantes que afetam a área:

- Referências urbanas principais;

- atividades e usos existentes;

- principais vetores de expansão;

- eixos viários principais;

- acessibilidades, principais meios de circulação e transporte existentes e previstos;

- planos existentes e legislação pertinente;

- áreas de recarga de aqüíferos e mananciais.

\section{ETAPA 2: Situação da área de estudo na bacia geográfica}

- Corredores de migração e polinização para flora e fauna;

- condicionantes fisiográficos (relevo, declividades, solos);

- drenagem superficial (linhas d'água, leitos de cheias, várzeas, nascentes);

- vegetação existente (tipos, distribuição, condições);

- aspectos microclimáticos (ventilação, insolação, fontes polvidoras);

- referências visuais (marcos, monumentos, paisagens únicas);

- levantamento das espécies da flora e da fauna mais significativos e seus hábitats.

Aconselha-se essas duas etapas serem realizadas especificamente por um grupo interdisciplinar de profissionais ligados às áreas ambientais, socioeconômicas e do planejamento (biólogos, geógrafos, ecologistas, sociólogos, economistas, engenheiros) e conduzidas por arquitetos e paisagistas. Os dados obtidos viriam dos levantamentos cartográficos e das visitas a campo. A sistematização cartográfica dos dados obtidos seria realizada a partir do método da sobreposição de layers - over lay - proposto por lan McHargh em seu método suitability analysis (MCHARGH, 1992). Em conjunto estaria a definição de mancha - corredor - matriz proposta por Forman (FORMAN; GODRON, 1986) e a identificação das diferentes unidades de paisagem ou unidades visuais (por ser uma área muito extensa) proposta por Robert Brown, conforme explanação nesse curso.

\section{ETAPA 3: As leituras da paisagem}

Em um terceiro momento da pesquisa, o último item explorado seria o fator social no campo da percepção da paisagem pela população fixa e móvel da área estudada. Para isso seria preciso incentivar a organização dessas comunidades, nos diferentes trechos da bacia do Córrego da Água Comprida, para facilitar a identificação de cada unidade de paisagem, permitindo que os profissionais das áreas sociais, junto dos arquitetos paisagistas, desenvolvessem oficinas e workshops para um melhor (re) conhecimento de cada grupo específico. 
Nessa etapa, o objetivo é que fossem traçadas leituras de paisagem a partir de caminhadas ao longo do córrego, de forma que a população ali existente tomasse conhecimento de toda sua forma e extensão. $\bigcirc$ contato com a vegetação existente, a percepção dos fluxos da água e seus ciclos e o entendimento de sua responsabilidade, com a preservação desses espaços, fazem-se intrínsecos ao processo de aprendizado e de conscientização de o homem poder reverter os processos responsáveis pela abertura de novas voçorocas na paisagem bauruense.

E, completando o ciclo, a abordagem do "espírito do lugar", aplicada em oficinas com adultos e com crianças. A proposta consiste em tentar transpor para o papel, na forma de desenho ou poesia, as diferentes sensações que o lugar oferece, podendo revelar as concepções de cada indivíduo ou grupo social para uma paisagem mais saudável e mais atraente.

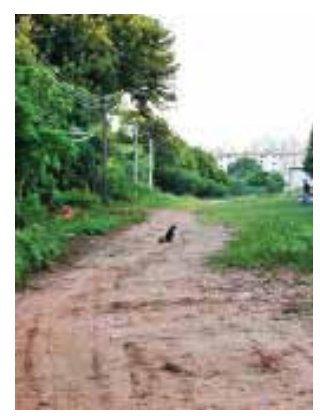

Figura 6: Área próxima ao córrego - Situação atual

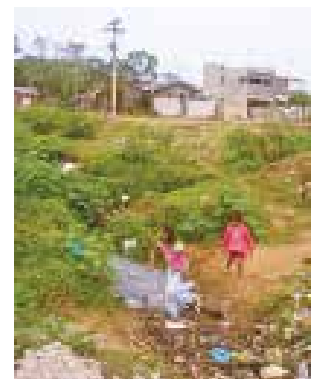

Figura 7: Jardim Nicéia: Crianças brincam à margem do córrego Situação atual Crédito: Grupo alunos TPI-3

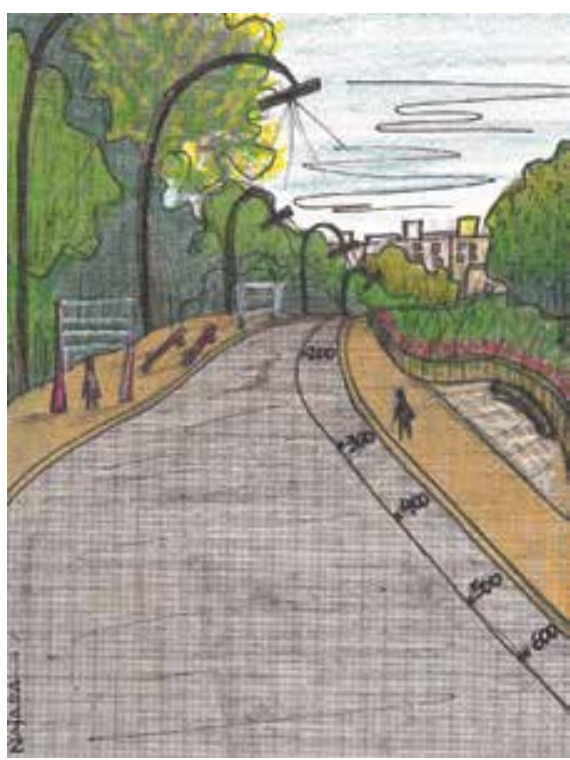

Figura 6A: Situação proposta Crédito: Autora

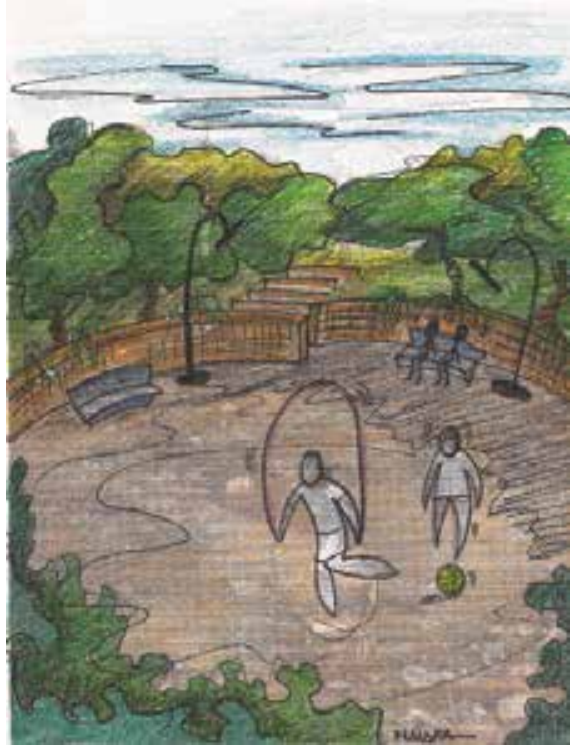

Figura 7A: Situação proposta Crédito: Autora 


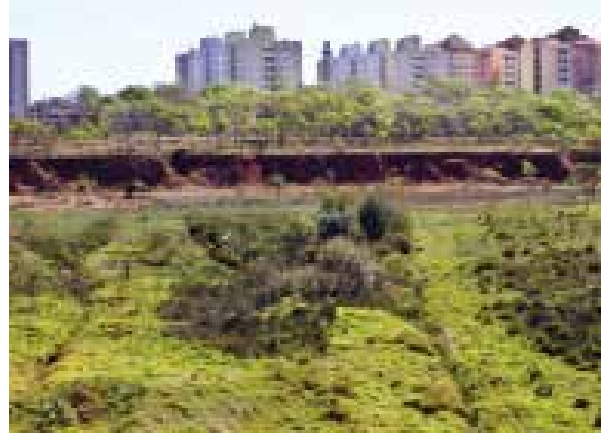

Figura 8: Condomínios verticais e erosão Situação atual

Crédito: Grupo alunos TPI-3

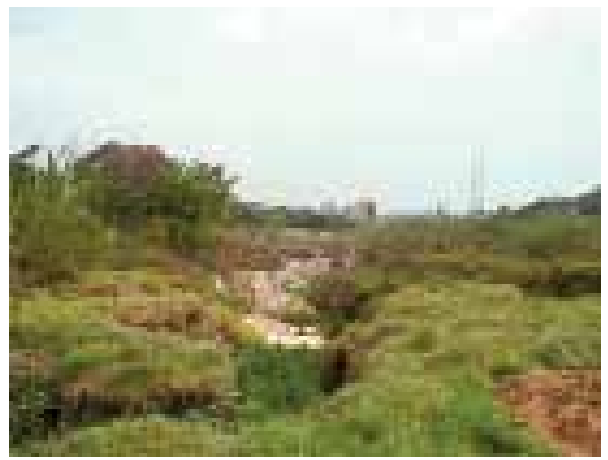

Figura 9: Vale do córrego da Água Comprida Situação atual

Crédito: Grupo alunos TPI-3

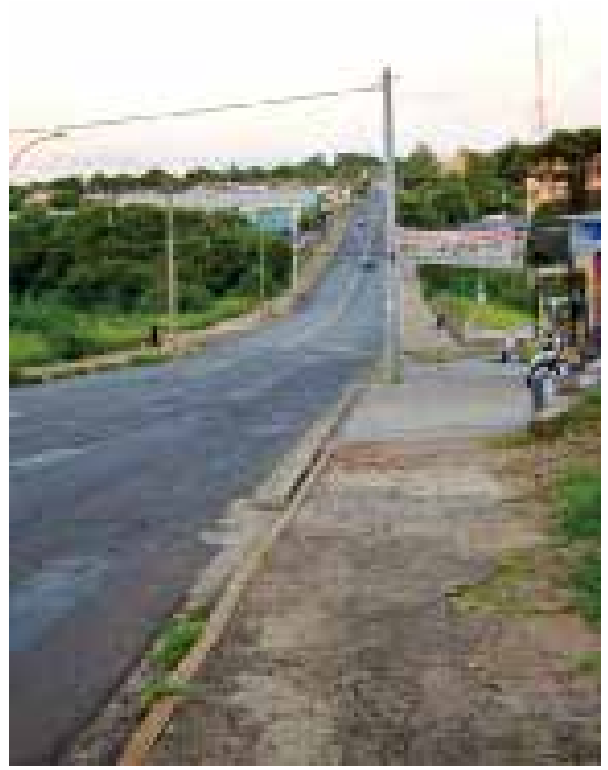

Figura 10: Avenida Cruzeiro do Sul - Situação atual Crédito: Autora

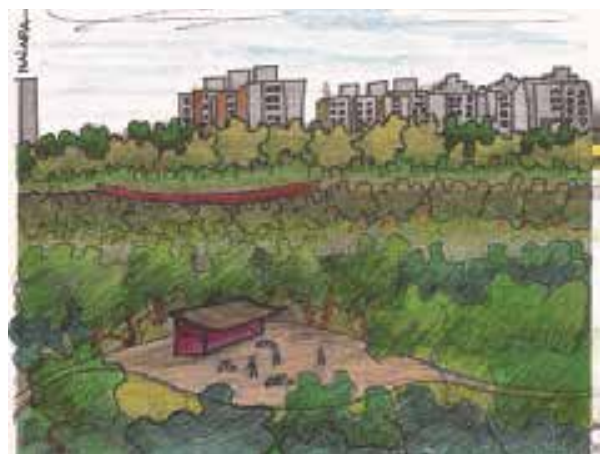

Figura 8A: Situação proposta Crédito: Autora

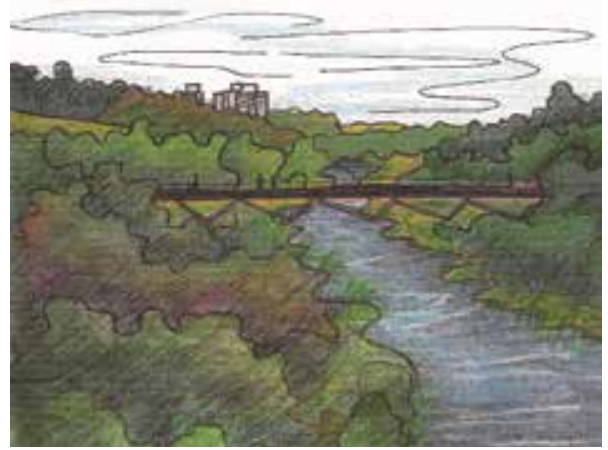

Figura 9A: Situação proposta

Crédito: Autora

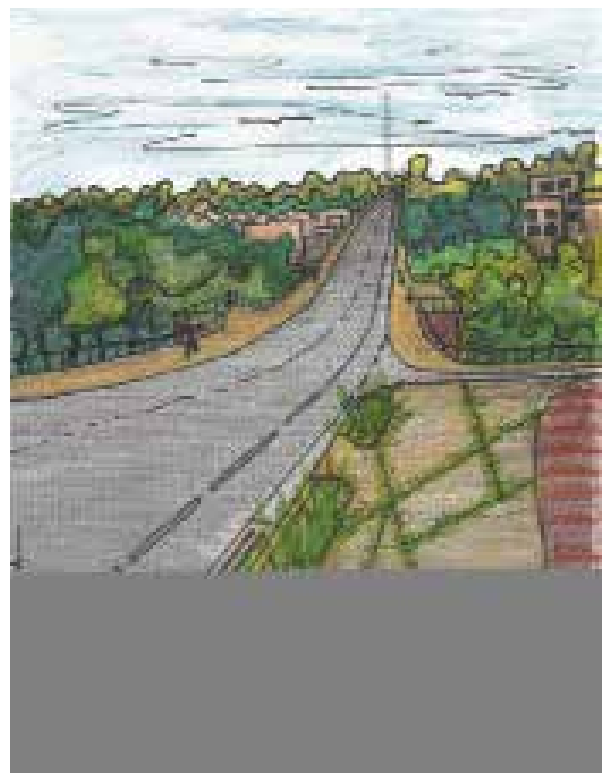

Figura 10A: Situação proposta

Crédito: Autora 


\section{A obtenção de dados}

Para o desenvolvimento deste trabalho, deixa-se claro que os dados aqui obtidos são um somatório de levantamentos realizados pela autora e complementados com levantamentos executados entre 2003 e 2005 por um grupo de alunos de graduação9 da disciplina TPI-3 (Trabalho Projetual Integrado) do curso de Arquitetura e Urbanismo da Unesp (Universidade Estadual Paulista - "Júlio de Mesquita Filho"), campus de Bauru.

Cada tema foi estudado por situações de campo, pelas bases cartográficas de órgão municipais e pelas fotos aéreas. Para facilitar a compreensão, as informações obtidas foram divididas de forma cartográfica em:

Aspectos socioculturais: Histórico dos loteamentos, vazios urbanos, usos do solo e carência de infra-estrutura.

Aspectos biofísicos: Inclinação e vegetação (nativa e ciliar).

\section{O Ideal}

"Think globally, plan regionally, act locally."

R. T. T. Forman

\section{A interpretação dos dados}

Para a interpretação das informações fica sugerido que caberia, ao grupo de profissionais, cruzar as informações e propor soluções que estivessem de acordo com os princípios dos processos ecológicos naturais e em harmonia com o ritmo e o cotidiano das populações locais, sendo as últimas fixas ou móveis. $\bigcirc$ caráter deste estudo parte do princípio de a análise interdisciplinar se mostrar ideal na obtenção dos resultados e mais eficaz na proposta das diretrizes.

A partir dos dados obtidos ${ }^{10}$ pelas diferentes formas de compreensão da área, estabeleceram-se algumas diretrizes para o planejamento da paisagem da bacia do Córrego da Água Comprida e foram sistematizadas cartograficamente em duas situações: unidades de paisagem e diretrizes para o planejamento de uma paisagem em Bauru. Essa sistematização levou em conta o critério de mancha-corredor-matriz e a área poderia ser dividida da seguinte maneira:

Mancha $=$ as grandes manchas poderiam ser os pontos nos quais se concentram as maiores porções de vegetação.

Corredor = a faixa de vegetação que acompanha a superfície de água corrente do Córrego, incluindo, nesse caso, a planície aluvial e parte de suas encostas (ver UPI, Figura 11).

Matriz $=$ a própria malha urbana em que está inserida a bacia do Córrego da Água Comprida. 


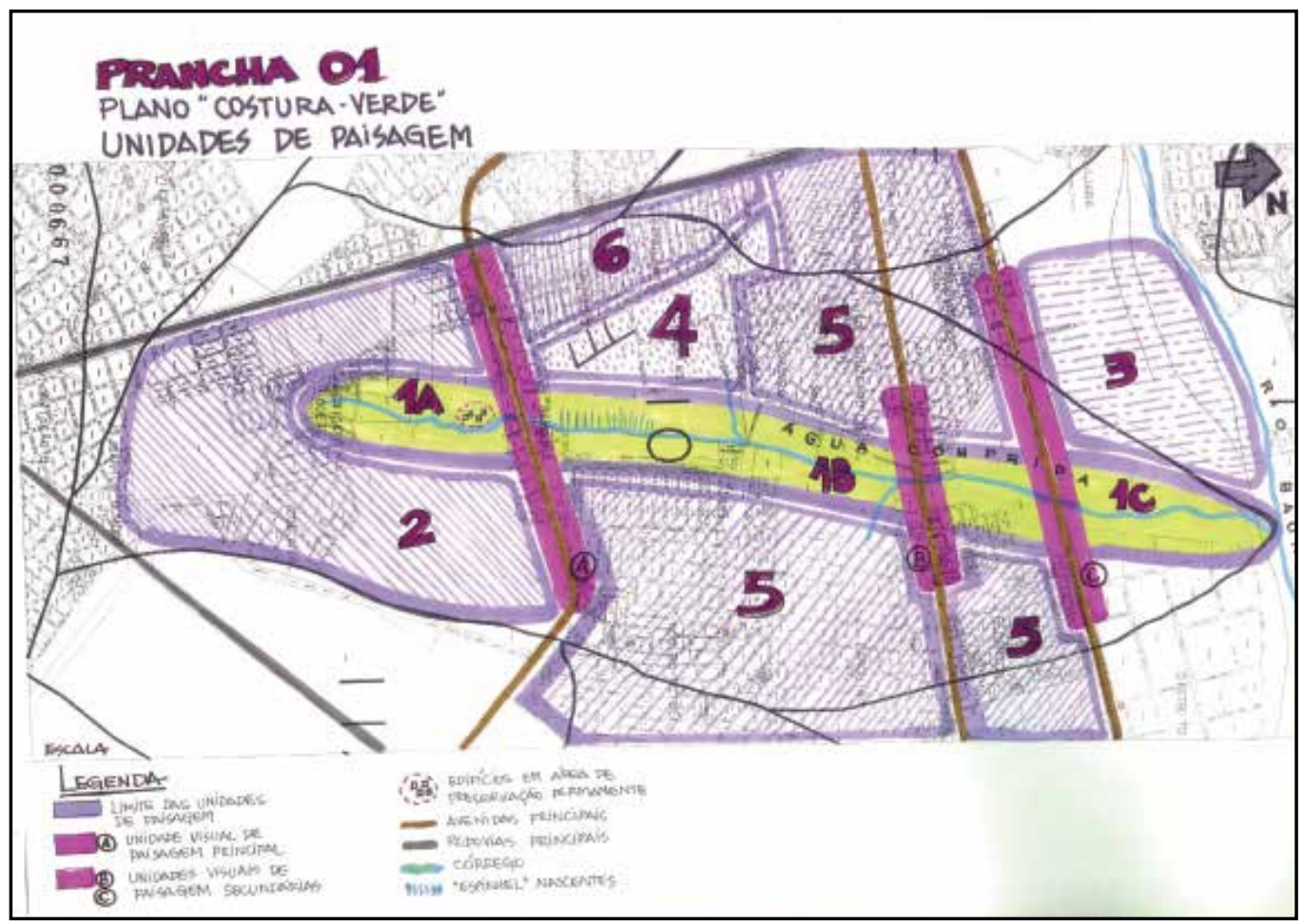

Figura 11: Proposta - Mapa 1 - Unidades de Paisagem Crédito: Autora

\section{A proposta: Plano "Costura-Verde"}

\section{Prancha 01: Unidades de Paisagem}

\section{Unidades de Paisagem (UP)}

\section{UP1 - Nascente, mata ciliar e várzea}

A - Nascente

- Áreas de conservação;

- severas restrições à especulação imobiliária e expansão urbana.

B - Nascente, mata ciliar e várzea

- Áreas de conservação ("espinhel" de nascentes);

- áreas de lazer ativo e/ou contemplação;

- severas restrições à especulação imobiliária e expansão urbana.

C - Mata ciliar e várzea

- Áreas de conservação;

- áreas de lazer ativo e/ou contemplação;

- severas restrições à especulação imobiliária e expansão urbana.

\section{UP2 - Áreas de interesse ecológico e paisagístico}

- Áreas de conservação;

- áreas de contemplação;

- controle da expansão urbana. 


\section{UP3 - Área de interesse ecológico e paisagístico}

- Áreas de conservação;

- áreas de contemplação;

- severas restrições à especulação imobiliária e expansão urbana.

\section{UP4 - Ocupação urbana vertical consolidada}

- Áreas de lazer ativo e/ou contemplação;

- expansão urbana restrita.

UP5 - Ocupação urbana com todas as suas funções e com grande densidade

- Áreas de lazer ativo e/ou contemplação;

- expansão urbana permitida para edificações com, no máximo, 4 (quatro) pavimentos, de modo a impedir a descaracterização dos bairros e a verticalização desenfreada em áreas periféricas;

- áreas residenciais com incentivo ao comércio e serviços locais para atender à demanda da área e desafogar o centro urbano.

\section{UP6 - Ocupação urbana com baixa densidade residencial}

Incentivo à expansão urbana com limitações.

\section{Unidades Visuais de Paisagem (UVP)}

UVP-A - Principal (Avenida Nações Unidas)

- Principal acesso entre o centro da cidade e as principais áreas de presença de mata nativa de cerrado: Jardim Botânico de Bauru, Zoológico Municipal e Campus da Unesp;

- situada em cota mais alta, próxima à montante, o que favorece a amplitude na apreensão visual da área;

- presença de muitos espaços livres (vazios urbanos) próximos ao córrego, de modo a proporcionar uma sensação de paisagem ampla e "natural" (ver microfilmagem no $C D)$.

\section{UVP-B - Secundária (Avenida Cruzeiro do Sul)}

- Via de ligação local, apenas entre as margens opostas do córrego;

- grande aglomeração urbana: sensação de paisagem "contida";

- situada em cotas mais baixas, não permite uma grande apreensão da extensão do vale.

\section{UVP-C - Secundária (Avenida Rodrigues Alves)}

- Um dos principais acessos da cidade, unindo o Distrito Industrial ao centro propriamente dito;

- apreensão da paisagem do Horto Florestal, porém o córrego não está totalmente evidenciado;

- sensação de desconexão visual entre o Horto Florestal (que possui grandes eucaliptos no perímetro da avenida) com os outros pontos do vale, onde se evidencia a vegetação do cerrado. 


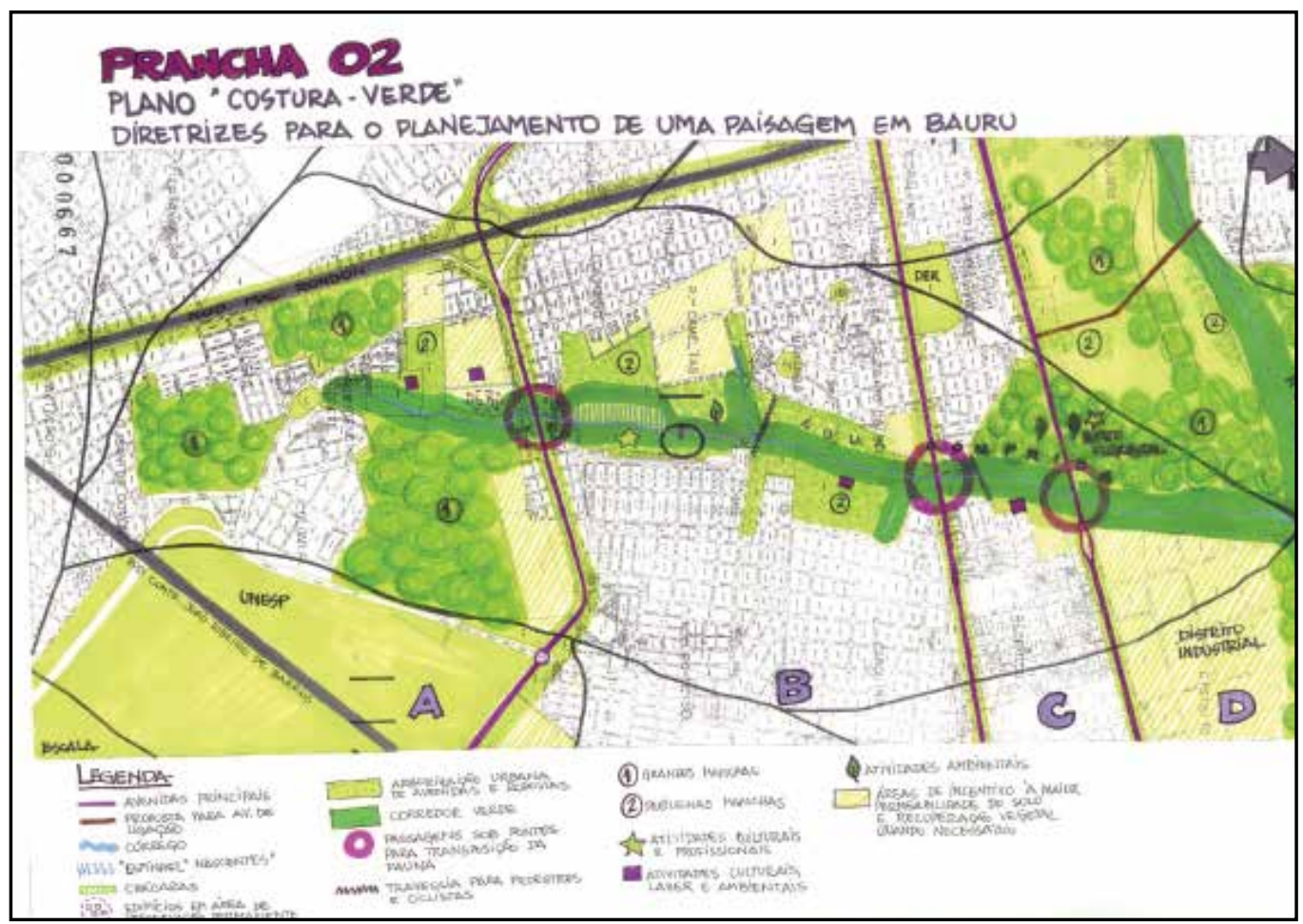

Figura 12: Proposta - Mapa 2 - Diretrizes para o planejamento de uma paisagem em Bauru Crédito: Autora

\section{Prancha 02: Diretrizes para o Planejamento de uma Paisagem em Bauru}

\section{Subárea A}

- Recuperação e conservação de mata ciliar;

- áreas de proteção e conservação do cerrado (manchas);

- área de acesso restrito à nascente;

- incentivo à educação ambiental com proposta de unidade de educação para adultos e crianças (em especial, no Jardim Nicéia e condomínios fechados) aliados a atividades culturais.

\section{Subáreas B e C}

- Recuperação de mata ciliar com definição das espécies mais apropriadas, preferencialmente com mudas vindas dos viveiros implantados ao longo do parque;

- manchas de proteção (grandes e pequenas) e conservação das espécies nativas do cerrado;

- área de proteção nos afloramentos de água, com recomposição vegetal e com visitação restrita e monitorada;

- implantação de parque linear, com atividades esportivas e infra-estrutura em ambas as margens do córrego; 
- transposições de margem única e exclusivamente para pedestres e ciclistas, no intuito de proteger a biodiversidade local das agressões causadas pelos impactos na construção de novas ligações viárias e, conseqüentemente, a polvição gerada pelos veículos automotores;

- margem à esquerda do córrego: implantação de unidade cultural e profissional para lazer, cultura, treinamento, aperfeiçoamento e capacitação profissional com cursos técnicos de formação para atender à demanda da área;

- incentivo à fixação, capacitação e potencialização de proprietários rurais na recuperação dos recursos naturais do parque;

- potencialização de atividades econômicas locais.

\section{Subárea D}

- Potencialização das atividades desenvolvidas no Horto Florestal, aliadas aos órgãos de proteção ambiental existentes em suas proximidades (Ibama, Polícia Ambiental, Departamento Estadual de Proteção dos Recursos Naturais-DEPRN, Instituto Ambiental Vidágua);

- incentivo a uma maior produção de mudas para a recomposição vegetal das diversas áreas do vale, de modo a transformar-se no grande laboratório de apoio para as aulas de educação ambiental;

- incentivo às atividades relacionadas à pesquisa da fauna e flora do lugar;

- potencialização dos espaços de lazer e cultura dentro do Horto Florestal, para que se configure como uma extensão do parque linear;

- incentivo às atividades profissionais ligadas à área ambiental: aulas de horticultura orgânica e jardinagem, com formação de profissionais aptos a trabalhar no manejo de espécies nativas e exóticas dentro da área de recuperação, proporcionando benefícios e empregos à comunidade local;

- incentivo às propriedades particulares para manter grande porcentagem de área permeável e recuperação vegetal com incentivos fiscais (no caso das empresas do Distrito Industrial) e redução de impostos municipais (no caso de proprietários particulares);

- proposta de construção de avenida para interligação com os bairros além rio Bauru (sentido norte-sul), de modo que a integração se faça de maneira efetiva em todas as microbacias da cidade.

\section{Propostas Complementares}

Além do sugerido pelos mapas anteriores, vale lembrar que o processo de análise da área utilizado nesse estudo também é aplicável em outras áreas lindeiras. No entanto, o que se propõe nessa breve análise é que os resultados obtidos são inerentes à paisagem urbana abordada. Porém, o estudo aqui mostrado pode, e deve, ser complementar aos planos das outras bacias adjacentes ao córrego, uma vez que a proposta dos corredores verdes foi feita para integrar os diferentes vales em um sistema maior: a ligação de toda a bacia do rio Bauru e seus afluentes por meio de corredores verdes. Esses corredores, 
além de integrar as diferentes unidades de paisagem do meio urbano em que estão inseridas, também promovem uma maior troca de material genético, tanto pela fauna como pela flora. Com passagens sob os "obstáculos" existentes (ruas, avenidas, viadutos), a migração de espécies contribui em maior diversificação do bioma urbano de Bauru. Além disso, a recomposição da vegetação feita, preferencialmente, com espécies nativas do cerrado, oferecem uma proteção mais eficaz aos solos arenosos da região. $\bigcirc$ estigma de vegetação retorcida" ${ }^{11}$ deveria ser enaltecido diante da beleza peculiar que nada mais é do que o resultado de uma adaptação dessas espécies vegetais ao solo desfavorável em nutrientes.

No que diz respeito à drenagem, pequenas soluções locais tomariam o caráter mitigador do drama vivido na cidade a cada período chuvoso. As casas deveriam ser equipadas com um recipiente - tipo cisterna - para conter as águas pluviais, cuja função pós-precipitação seria para afazeres domésticos de uso não-pessoal: lavagem de autos, irrigação de jardins, lavagem de quintais. As áreas de piso deveriam, incentivadas pela legislação municipal, obedecer a um índice mais rígido de permeabilidade do solo em novas construções e nas que estivessem sendo reformadas. Já que em Bauru a implantação de estações para o tratamento de esgoto é muito incipiente, algumas medidas como a interceptação dos resíduos sólidos antes de esses atingirem o leito dos cursos d'água se apresenta não como uma solução definitiva, mas como o início de um longo processo paisagístico-urbano-ambiental para que tais águas, um dia, alcancem baixos índices de polvição.

Entretanto, para que uma nova consciência tome conta da população que vivencia ou mora em áreas ribeirinhas, firma-se a necessidade de um programa nas escolas, públicas e privadas, e às comunidades em geral, de esclarecimento in loco de como é possível preservar a natureza dentro do próprio bairro, dentro da própria cidade. São meios propostos para isso:

- A informação e conscientização dos benefícios em preservar-se a vegetação urbana e de matas ciliares dos córregos e rios que cortam a malha urbana;

- esclarecimentos quanto ao reuso das águas servidas, com visitas monitoradas aos alagados construídos - wetlands - do Jardim Botânico de Bauru;

- educação para o lixo reciclável e uma maior efetivação da coleta seletiva nas comunidades.

\section{CONSIDERAÇÕES FINAIS}

Conforme dito no início, o trabalho aqui desenvolvido se apresentou como uma proposta para diretrizes no planejamento do desenvolvimento sustentável das áreas residuais em áreas de fundo de vale, na paisagem urbana de Bauru. Acredita-se na potencialidade do lugar para a implantação de novos modos de concepção da paisagem, de uma maneira lógica e coerente com as realidades vividas no mundo de hoje.

Desse modo, faz-se necessária a interdisciplinaridade nos processos para o planejamento sustentável da paisagem, com a fundamental participação da população para 
a consolidação de um verdadeiro sistema de valores. Sistema esse no qual o planejamento ecológico da paisagem possa atuar como instrumento de recuperação ambiental e integração social em todas as bacias dos rios e córregos da cidade, revertendo em qualidade de vida e em um desenvolvimento sustentável para o ecossistema urbano.

Com mais essa pesquisa espera-se que, em âmbito ainda maior de intenção, a área estudada possa, futuramente, ser apenas um dos inúmeros elos "verdes" que interligarão uma trama ainda maior, um grande sistema de corredores verdes por toda a malha urbana. Ao unir córregos e rios urbanos, as espécies, vegetais e animais, encontrarão um meio mais favorável ao aumento de sua biodiversidade, protegidos e assistidos pelo cidadão, em convivência harmoniosa. Espetáculo sublime para que nossas futuras gerações assistam surgir, retorcida e não só em belezas amarelas, a doce trama do cerrado.

\section{Notas}

(1) Hurbano: o termo foi criado pela contração proposital das palavras humano e urbano; em nosso entendimento, esses são fatores intrínsecos às transformações ocorridas na paisagem natural em quase todas as cidades de médio a grande porte do país.

(2) Cinzeiro ou Pau-de-Tucano (Vochysia tucanorum): árvore-símbolo do Jardim Botânico de Bauru.

(3) "'Pós-modernidade', no contexło da produção do cotidiano, em termos gerais, é a reprodução de um modo de vida urbano que evidencia a cultura de massas e a globalização." (CARLOS, 1996)

(4) Tradução livre da autora.

(5) Na época da pesquisa, o Plano Diretor Participativo estava sendo elaborado.

(6) Ver trajetória cronológica no artigo "Pode-se Planejar a Paisagem?" (PELLEGRINO, 2000, p. 163-167).

(7) Explanação proferida no curso citado.

(8) $\bigcirc$ quadro-esquema foi montado conforme os temas apresentados mais relevantes para essa pesquisa durante o curso em questão. $O$ somatório de alguns desses tópicos se afirmaram como aplicáveis entre si, de modo que tanto a natureza quanto o homem e, respectivamente, seus processos naturais e sociais, possam confirmar a evidência do ecossistema urbano sem que nenhuma das partes seja estranha ou agressiva à outra. Espera-se, assim, que os processos naturais de drenagem, ciclo hidrológico, formação do solo, clima urbano, fauna e flora estejam mais claros e evidentes para o homem.

(9) Mapas dos levantamentos e foto aérea da bacia do Córrego da Água Comprida: Créditos - Grupo TPI-3 Unesp (Catarina Klein, Julio Tescano, Laura Bigliassi e Romina Arivalo).

(10) Para a conclusão desse estudo, tomou-se apenas a interpretação dos dados feita pela autora, uma vez que o objetivo se concentra em ilustrar o processo sugerido no planejamento da paisagem.

(1 1) A vegetação do Bioma do Cerrado, considerado aqui em seu lato sensu, não possui uma fisionomia única em toda sua extensão. Bastante diversificada, apresenta desde formas campestres bem abertas, como os campos limpos de cerrado, até formas relativamente densas, florestais, como os cerradões. Caracteriza-se pelo estrato lenhoso, constituído por árvores e arbustos, no qual seu adensamento acaba por eliminar, em grande parte, o estrato herbáceo. Troncos e ramos tortuosos, súber espesso, macrofilia e esclerofilia são características da vegetação arbórea e arbustiva, que, de pronto, impressionam o observador. $O$ sistema subterrâneo, dotado de longas raízes pivotantes, permite a essas plantas atingir 10, 15 ou mais metros de profundidade, abastecendo-se de água em camadas permanentemente úmidas do solo, até mesmo na época seca. Fonte: http://eco. ib.usp.br/cerrado/aspectos_vegetacao.htm. 


\section{Bibliografia}

ALVES, José Xaides de Sampaio. Voçorocas do poder público: Na lei, na forma e gestão urbana na "cidade sem limites". 2001. Tese (Doutorado) - Faculdade de Arquitetura e Urbanismo, Universidade de São Paulo, São Paulo, 2001.

BAURU, Prefeitura Municipal de Bauru. Plano diretor de desenvolvimento integrado. Bauru: Prefeitura de Bauru, 1996.

CARLOS, Ana Fani Alessandri. O lugar no/do mundo. São Paulo: Hucitec, 1996.

CHACEL, Fernando Magalhães. Paisagismo e ecogênese. Rio de Janeiro: Fraiha, 2001.

CONSTANTINO, Norma Regina Truppel. Sistema de áreas verdes para a cidade de Bauru. 1995. Dissertação (Mestrado) - Faculdade de Arquitetura, Artes e Comunicação, Universidade Estadual Paulista, São Paulo, 1995.

A construção da paisagem de Bauru: Os fundos de vale. 2005. Tese (Doutorado) - Faculdade de Arquitetura e Urbanismo, Universidade de São Paulo, São Paulo, 2005.

CURITIBA. Prefeitura. Instituto de Pesquisa e Planejamento Urbano de Curitiba. Diretrizes para a preservação de fundos de vale. Curitiba: IPPUC, 1991.

DRAMSTAD, W. E.; OLSON, J. D.; FORMAN, R. T. T. Landscape ecology: Principles in landscape architecture \& landuse planning. Island Press: Washington, D. C., 1996.

FABOS, J. G. Planning the total landscape: A gujde to intelligent land use. Westview Press: Boulder, 1979.

\& AHERN, J. Greenways: The begninning of an international movement. Elsevier: Nova York, 1996.

FORMAN, Richard T. T.; GODRON, Michael. Landscape ecology. Wiley: Nova York, 1986.

GHIRARDELLO, Nilson. Aspectos do direcionamento urbano da cidade de Bauru. 1992. Dissertação (Mestrado) - Escola de Engenharia de São Carlos, Universidade de São Paulo, São Carlos, 1992.

HOUGH, M. Naturaleza y ciudad. Planificación urbana y procesos ecológicos. Barcelona: Gustavo Gilli, 1995.

JACOBS, Jane. Morte e vida de grandes cidades. São Paulo: Martins Fontes, 2000.

JELLICOE, Geoffrey and Susan. The ladscape of man. Londres: Thames and Hudson, 1996.

KAPLAN, R.; KAPLAN, S. The experience of nature: A psychological perspective. Cambridge University Press: Cambridge, 1989.

KLEIN, Aldo Luiz (Org.). Eugen Warming e o cerrado brasileiro. São Paulo: Unesp/Imprensa Oficial, 2002.

KRONKA, Francisco; NALON, Marco Aurélio; MATSUKUMA, Ciro Koiti. Áreas de domínio do cerrado no estado de São Paulo. São Paulo: Secretaria do Meio Ambiente, 1998.

LEITE, Maria Ângela Faggin Pereira. Destruição ou desconstrução. Questões da paisagem e tendências de regionalização. São Paulo: Hucitec/Fapesp, 1994.

LYLE, John Tillman. Design for human ecosystems. Nova York: Van Nostrand, 1985.

MACEDO, Silvio Soares. Quadro do paisagismo no Brasil. São Paulo: Edusp, 1999.

MAGALHÃES, Manuela Raposo. A arquitectura paisagista. Lisboa: Editorial Estampa, 2001.

MCHARGH, lan L. Design with nature. Wiley: Nova York, 1992.

ODUM, Eugene. Ecologia. São Paulo: Livraria Pioneira Editora/Edusp, 1969.

OSEKI, Jorge Hajime; PELLEGRINO, Paulo R. M. Capítulo 8. Sociedade e Ambiente, São Paulo, 2003.

PAINE, Cecelia; TAYLOR, James R. Cultural landscape assessment: A comparison of current methods. Landscape Research Group at Guelph: Guelph, 1995.

PEIXOTO, Nelson Brissac. Paisagens urbanas. São Paulo: Senac/Marca D’Água, 1996.

. O olhar do estrangeiro. In: NOVAES, Adauto (Org.). O olhar. 7. ed. São Paulo: Companhia das Letras, 2002.

PELLEGRINO, Paulo R. M. Pode-se planejar a paisagem? Paisagem e Ambiente - Ensaios. São Paulo: FAUUSP, n. 13, 2000.

RODRÍGUEZ, J. A. C. El espacio libre urbano como ambiente restaurador: modalidades de uso y tipos de usuarios. In: SEMINARIO HISPANICO-PORTUGUES SOBRE JARDINES Y ESPACIOS ABIERTOS, 1969, Sevilha. Anais... Sevilha: Unesco, 1989.

ROMERO, Marta Adriana Bustos. Arquitetura bioclimática do espaço público. Brasília: Editora da Universidade de Brasília, 2001. 
SANTOS, Milton. A natureza do espaço. Técnica e tempo. Razão e emoção. São Paulo: Hucitec, 1996.

SILVA, A. N. R. da.; SOUZA, L. C. L. de; MENDES, J. F. G. M. Planejamento urbano, regional, integrado e sustentável. São Carlos: EESC-USP, 2005.

SPIRN, Anne Whiston. O jardim de granito. A natureza no desenho da cidade. São Paulo: Edusp, 1995.

TUAN, Yi-Fu. Topofilia. Um estudo da percepção, atitudes e valores do meio ambiente. São Paulo: Difel, 1980.

ZUKIN, Sharon. Paisagens urbanas pós-modernas: Mapeando cultura e poder. In: ARANTES, Antonio A. (Org.) O espaço da diferença. Campinas: Papirus, 2000.

\section{Sites}

www.vidagua.org.br

www.eco.ib.usp.br/cerrado

www.ibama.com.br

www.mre.gov.br/cdbrasil/itamaraty/web/port/meioamb/ecossist/cerrado

Agradecimentos aos alunos da disciplina TPI-3 (Catarina Klein, Julio Tescano, Laura Bigliassi e Romina Arivalo), Departamento de Geoprocessamento do DAE-Bauru, Karina Trevisan F. Ferraz, Kelly C. Magalhães Faria (FAAC/Unesp) e Laura B. de Castro. 
